\title{
Preventing Stroke with a Plant-Based Diet
}

\author{
Stewart Rose and Amanda Strombom* \\ Plant-Based Diets in Medicine, USA \\ Submission: August 05, 2020; Published: September 29, 2020 \\ *Corresponding author: Amanda Strombom, Plant-Based Diets in Medicine, 12819 SE 38th St, \#427, Bellevue, WA 98006, USA
}

Abstract

Current known modifiable risk factors for stroke together account for more than $90 \%$ of population attributable risk. A plant-based diet has been shown to reduce the risk of stroke by $28-48 \%$, and to significantly reduce the biggest risk factors - hypertension, coronary heart disease, and type 2 diabetes. Vegetarians have been found to have a $34-44 \%$ lower risk of developing hypertension, and a $40 \%$ reduced risk of ischemic heart disease. Vegans have a $78 \%$ lower risk of type 2 diabetes and a $75 \%$ reduced risk of hypertension compared to meat eaters with an otherwise healthy lifestyle. In addition, plant-based diets may reduce the likelihood of other risk factors that are associated with stroke, such as atrial fibrillation and heart failure. One of the main goals in stroke risk reduction is to control vascular risk factors such as hypertension, diabetes, dyslipidemia, and smoking cessation. Changes in lifestyle such as a healthy diet and aerobic exercise are recommended strategies for all of these. Patient compliance on plant-based diets has been good in almost all studies, with the degree of compliance often very high. The patient should be informed that while a plant-based diet reduces the risk of stroke, it will also reduce the risk of a number of other diseases.

Keywords: Atrial fibrillation; Hemorrhagic stroke; Hypertension; Ischemic stroke; plant-based diet; stroke; Vegetarian; Vegan

Abbreviations: AF: Atrial Fibrillation; ApoB/ApoA1: Apolipoprotein Ratio; BP: Blood Pressure

CAD: Coronary Artery Disease; CHD: Coronary Heart Disease; CRP: C-Reactive Protein; HDL: High Density Lipoprotein; HF: Heart Failure; hsCRP: High sensitivity C-reactive Protein; LDL: Low Density Lipoprotein tPA; Tissue Plasminogen Activator

\section{Introduction}

Nearly 800,000 people suffer from a stroke each year in the United States. Stroke is the fifth leading cause of adult death and disability. With up to $40 \%$ of survivors not expected to recover independence from severe disabilities, it results in over $\$ 72$ billion in annual cost in the US alone [1]. Stroke results in immense human suffering, and an excessive financial burden on health systems worldwide. Treatment is difficult hence prevention strategies are all the more important. Therefore, physician education on stroke prophylaxis with a plant-based diet would be especially valuable in preventing the incidence of stroke. Stroke is a heterogeneous, multifactorial disease regulated by modifiable and nonmodifiable risk factors. Modifiable factors include a history of hypertension, diabetes mellitus, C-Reactive Protein (CRP), high sensitivity CRP (hsCRP), and coronary heart disease amongst others. Nonmodifiable factors include age, sex and race. Other less-well documented risk factors include geographic location, socioeconomic status and alcoholism. Approximately $80 \%$ of stroke events could be reduced by making simple lifestyle modifications [2].
The majority, 82-92\%, of strokes are ischemic although the relative burden of hemorrhagic versus ischemic stroke varies among different populations [3]. Hemorrhagic strokes can be either primarily intraparenchymal or subarachnoid. Ischemic stroke can be further divided into what have been referred to as etiologic subtypes, or categories thought to represent the causes of the stroke: cardioembolic, atherosclerotic, lacunar, other specific causes (dissections, vasculitis, specific genetic disorders, others), and strokes of unknown cause [4]. As far as treatment goes, the intravenous administration of tissue plasminogen activator (tPA) within 3 hours of stroke onset, or within 4.5 hours of stroke onset in select patients, is currently the only U.S. Food and Drug Administration (FDA)-approved therapy for ischemic stroke [5]. Because of the time-dependent nature of tPA therapy and a fear of hemorrhagic complications, only $1 \%-8 \%$ of potentially eligible patients have been treated with tPA [6]. Mechanical thrombectomy may also be performed. Restoring blood flow can mitigate the effects of ischemia only if performed quickly. Mechanical clot disruption is an alternative for patients in whom fibrinolysis is 
ineffective or contraindicated [7]. In the case of cardioembolism due to atrial fibrillation, mechanical valves, or cardiac thrombus, anticoagulation is the mainstay of therapy (8). In contrast to treatment for ischemic stroke, the recommendation for managing hemorrhagic stroke is supportive treatment, because no specific medication has been developed $[9,10]$. Therefore, treatments for acute ischemic and hemorrhagic stroke continue to be a major unmet clinical need, making prevention even more important.

\section{Risk Factors}

Some risk factors of stroke are nonmodifiable, such as older age and male sex. Current known modifiable risk factors -hypertension, current cigarette smoking, high waist-to-hip ratio, poor diet, lack of regular physical activity, diabetes mellitus, alcohol consumption, psychological factors, cardiac causes, and apolipoprotein (ApoB/ApoA1) ratio - together account for more than $90 \%$ of population attributable risk for stroke [11,12]. Risk factors for hemorrhagic and ischemic stroke are similar, but there are some notable differences. There are also differences in risk factors among the etiologic categories of ischemic stroke. Hypertension isa particularly importantriskfactorfor hemorrhagic stroke, though it contributes to atherosclerotic disease that can lead to ischemic stroke as well. Hyperlipidemia, on the other hand, is a particularly important risk factor for ischemic strokes due to atherosclerosis of extracranial and intracranial blood vessels, just as it is a risk factor for coronary atherosclerosis. Recent evidence has firmly established heart failure as a risk factor for stroke, most commonly for ischemic stroke [13]. Metabolic syndrome and high Low-Density Lipoprotein (LDL) cholesterol have also been identified as risk factors for intracranial atherosclerosis, an important mechanistic step in the pathogenesis of ischemic stroke [14].

Atrial Fibrillation (AF) is also a risk factor for cardioembolic stroke [11].

\section{Impact of diet}

According to the American Heart Association statistical report of 2015 , only $0.1 \%$ of Americans consume a healthy diet and only $8.3 \%$ consume a moderately healthy diet [1]. Within the last decades, plant-based nutrition has experienced increased interest in the medical community, because it can reduce the risk factors of diseases such as hypertension [15], type 2 diabetes [16], and coronary heart disease [17]. Generally, a Mediterranean diet is a much more plant-rich diet than the standard American diet. In one Dutch cohort followed for 10-15 years, those with the highest adherence to the diet had an adjusted relative risk of incident stroke of $30 \%$ less than compared to those with the lowest adherence [18]. In one study comparing vegetarians to nonvegetarians who otherwise practice a healthy diet, a $29 \%$ reduction in the risk of stroke was noted [19]. In another study, researchers found vegetarians had a $48 \%$ lower risk of overall stroke than non-vegetarians, a $60 \%$ lower risk of ischemic stroke, and a $65 \%$ lower risk of hemorrhagic stroke [20]. However, one study did show an increased risk of hemorrhagic stroke [21] Nearly $80 \%$ of vegetarians in this study drank varying degrees of alcohol. Alcohol consumption (as measured by $\gamma$-glutamyl transferase) has been suggested in a previous cohort study to modify the effect of low serum cholesterol typical of vegetarians on hemorrhagic stroke risk [22]. Dietary intake of fruits and vegetables may reduce the risk of stroke. These foods may protect against stroke through antioxidant mechanisms or by raising potassium levels [23-25].

\section{Dyslipidemia}

Vegetarians have a $40 \%$ reduced risk of ischemic heart disease $[19,26]$. Epidemiological research also points to the lower total cholesterol and LDL cholesterol levels in those already following plant-based diet. One study showed that vegans had on average a total cholesterol of only $142 \mathrm{mg} / \mathrm{dl}$ and an LDL cholesterol of only $69 \mathrm{mg} / \mathrm{dl}$ [27]. Other studies have also shown a much lower than average level of total cholesterol and LDL $[28,29]$. One study showed am LDL/HDL ratio 1.63 for vegans compared to 2.27 for meat eaters. [28] Vegans have also been shown to have lower ratios of ApoB/Apo1 ratios [17,30,31]. A newer area of research has focused on the role of the gut microbiota in the pathogenesis of atherosclerosis. It has been found that vegetarians and vegans have bacterial flora that produce less trimethylamine-N-oxide (TMAO), thought to be atherogenic, than the flora of meat eaters [32]. Several studies found an association between high serum CRP level and development of stroke [33-37] Rooco et al. found an independent association between high serum CRP level with mortality and intracerebral hemorrhage after thrombolysed stroke [38]. Lower levels of hs-CRP were found in those following a vegetarian diet for more than 2 years $[39,40]$. An interventional study found that after 8 weeks on a vegan diet hs-CRP was reduced $32 \%$ even more than the American Heart Association diet [41].

\section{Hypertension and Type 2 Diabetes}

DASH (dietary approaches to stop hypertension) was developed by the National Heart, Lung, and Blood Institute to help people prevent high blood pressure. The plan focuses on eating plenty of fruits, vegetables, and whole grains while lowering salt. Adherence to the DASH-style diet is associated with a lower risk of stroke among middle-aged women during 24 years of follow-up [42]. Studies have found that vegans and vegetarians have lower blood pressure than their meat-eating counterparts. Observational studies have found that vegetarian diets are associated with a $6.9 \mathrm{mmHg}$ lower mean systolic blood pressure and $4.7 \mathrm{mmHg}$ lower mean diastolic blood pressure compared to omnivorous diets. Clinical trials of vegetarian or vegan diets of at least 6 weeks duration resulted in mean decreases of $4.8 \mathrm{mmHg}$ systolic BP and $2.2 \mathrm{mmHg}$ diastolic BP [43]. This finding may, in part, be related to increased potassium intake from plant foods (particularly if accompanied by a low sodium intake). A high sodium to potassium ratio has been associated with increased 
risk of stroke [15]. In a prospective cohort study of 1546 nonhypertensive subjects followed for three years, those consuming more phytochemical rich foods (plant-based foods) had lower risk of developing hypertension [44]. In a matched cohort study of 4109 non-hypertensive subjects followed for a median of 1.6 years, vegetarians had a 34\% lower risk of developing hypertension than non-vegetarians [45]. In a study comparing black vegetarians with non-vegetarians who had a healthy lifestyle, the risk of hypertension was reduced 44\% [46]. Diabetes causes various microvascular and macrovascular changes often culminating in major clinical complications, one of which, is stroke [47]. Vegans have a 78\% lower risk of type 2 diabetes and a $75 \%$ reduced risk of hypertension compared to meat eaters with an otherwise healthy lifestyle lifestyle [48].

\section{Atrial fibrillation}

Atrial fibrillation can lead to thrombus development within the atria [49], particularly the left atrial appendage [50-51] which can cause thromboembolic events. Multiple risk factors and clinical conditions that are associated with the development and progression of AF have been identified in the last decades [5253]. Although there are several nonmodifiable risk factors, such as gender or advancing age, a gradual shift in awareness toward modifiable predisposing conditions has been observed [54]. Conventional cardiovascular risk factors that are associated with atrial fibrillation include hypertension, coronary heart disease, heart failure, and valvular heart disease [52, 55]. Other wellestablished concomitant risk factors include diabetes, overweight, obesity, and hyperthyroidism. Additionally, there are a number of emerging and less well-researched risk factors, such as subclinical atherosclerosis, inflammation, obstructive sleep apnea, and chronic kidney disease [56]. Plant-based diets may reduce the likelihood of many traditional risk factors that are associated with AF [56], including hypertension [43, 57, 58], hyperthyroidism [59-60], obesity [48], and diabetes [16]. One study showed that a vegan diet reduced the risk of hyperthyroidism by $51 \%$ while a vegetarian diet reduced the risk by $28 \%$ showing a dose response relationship [60]. Several lines of epidemiological research have also shown a lower risk of chronic kidney disease among vegetarians. It also shows a substantially increased risk among omnivores, especially those who eat red and processed meats [61].

Contrary to recent interest, both fish and fish oil do not seem to have an antiarrhythmic effect or protect against atrial fibrillation $[62,63]$.

\section{Heart failure}

Traditionally, the following are the known causes of ischemic stroke:

(a) embolism to the brain of cardiac or aortic origin (i.e., myocardial infarction, AF, valvular heart disease, complicated aortic plaque, or patent foramen ovale);

(b) cerebral ischemia due to perfusion failure and artery-toartery embolism (i.e., large artery atherosclerotic plaque, small vessel disease or occlusion, or vasculitis); and

(c) thrombosis (prothrombotic state). Not surprisingly, heart failure (HF) comprises all of these [13].

Several epidemiological investigations have identified the following key risk factors for heart failure: increasing age, hypertension, coronary artery disease, diabetes, obesity, valvular heart disease, and the metabolic syndrome [64].

Since those following a plant-based diet are at lower risk of coronary artery disease, diabetes and obesity, they can be expected to be at lower of heart failure as well. Several population-based cohort studies that have demonstrated an inverse relationship between increased consumption of plant-based foods and incidence of heart failure [65-69]. Five prospective studies examined the association between meat consumption and HF incidence in separate medium to large, middle-aged cohorts. All of these studies found increased HF risk with meat consumption [70-74]. In a prospective cohort study of 21,275 participants from the Physicians' Health Study I, consumption of one egg a day increased the risk of heart failure by $28 \%$ and consuming two eggs a day increased the risk of heart failure by $64 \%$ [75]. In another prospective study of over 15,000 participants, those who ate a plant-based diet most of the time had a $42 \%$ reduced risk of heart failure [76]. The beneficial effects of a low-fat vegetarian diet are indicated for patients at risk of heart failure and who also have CAD. One study showed significant improvements in such patients with documented CHD, regardless of ejection fraction, in lifestyle behaviors, body weight, body fat, blood pressure, resting heart rate, total and LDL-cholesterol, exercise capacity, and quality of life by 3 months. Most improvements were maintained over 12 months [77].

A recent case report demonstrated the effects of a plant-based diet in a 79-year-old male with documented triple vessel disease (80-95\% stenosis) and left ventricular systolic dysfunction (ejection fraction 35\%) in the context of progressive dyspnea. Two months on a plant-based diet led to clinically significant reductions in body weight and lipids, with improved exercise tolerance and ejection fraction (+15\%) [69]. In another case study, a 54-year-old female with grade 3 obesity (body mass index (BMI) $45.2 \mathrm{~kg} / \mathrm{m}^{2}$ ) and type II diabetes (hemoglobin A1c $8.1 \%$ ), coronary artery disease with a $30 \%$ proximal left anterior descending artery stenosis, a 25\% proximal and a $60 \%$ distal left circumflex artery stenosis, and a $65 \%$ first obtuse marginal artery lesion. Echocardiography revealed a left ventricular ejection fraction of $25 \%$ without significant valvular pathology; heart failure was diagnosed. After 5 months on a plant-based diet, her baseline dyspnea on exertion improved considerably. Repeat echocardiography revealed a normal left ventricular ejection 
fraction of 55\% [78] Comorbid diabetes showed a reduction of HbA1c from her diabetes resolved, with her hemoglobin A1c falling from $8.1 \%$ to $5.7 \%$ without the use of diabetes medications.

\section{Clinical Considerations}

One out of four strokes is recurrent. Secondary stroke prevention starts with deciphering the most likely stroke mechanism. One of the main goals in stroke risk reduction is to control vascular risk factors such as hypertension, diabetes, dyslipidemia, and smoking cessation. Changes in lifestyle such as a healthy diet and aerobic exercise are recommended strategies for all of these. In general, a plant-based diet, low salt intake, and a limited intake of saturated fats and simple sugars are likely to have significant cardiovascular benefits in the secondary prevention of stroke [8]. Patient compliance on plant-based diets has been good in almost all studies. The degree of compliance has often been very high. For instance, one study obtained a 99\% compliance [79]. In a 22 -week study $94 \%$ of subjects on a vegan diet were compliant [80]. In a somewhat longer study, $84 \%$ of the participants in each group completed all 24 weeks [81]. In studies of patients placed on plant-based diets for coronary artery disease, high compliance has been noted even over several years. For instance, one study of patients placed on a plant-based diet showed $89 \%$ compliance for 3.7 years [82].

Compliance may be enhanced when the rationale for the treatment, and that the treatment is backed by research, is explained to the patient [83]. The doctor should prescribe the treatment by writing it down on a prescription form or other stationery with the physician's name on it. This written prescription is not only valuable to the patient but can also be valuable in enlisting the support of family, friends and social contacts. Vegetarian and vegan diets and food are not as uncommon as they used to be. The sales and availability of meat and dairy substitutes are have grown enormously in recent years. These products make dietary changes much easier in most cases, and when combined with a diet composed of vegetables, whole grains, fruits, legumes and nuts they can be very healthy. When starting the patient on a plant-based diet, foods with high levels of dietary fiber should be introduced slowly to avoid flatulence. When prescribing a plant-based diet for the prevention of stroke, many patients may already be being treated with other medications for other pathologies. Patients concurrently being treated for type II diabetes, hypercholesterolemia, coronary artery disease, hypertension and other pathologies such as rheumatoid arthritis, ulcerative colitis and Crohn's disease, can be treated with a plant-based diet. Medications being prescribed for any of these pathologies may need to be titrated as the effects of the plant-based diet become evident.

For instance, a plant-based diet is more effective for treating type II diabetes than Metformin. The dosage may have to be titrated down as blood glucose is lowered. Similarly, a plant-based diet is as efficacious in treating hypercholesterolemia as Lovostatin [84]. The plant-based diet is also very effective for treating angina pectoris, with patients experiencing a $91 \%$ decrease in frequency [85]. It may take several weeks to two months for the full effect to take place. Lab work should be done with this time factor in mind. A bit of patience on the part on the part of the patient is necessary for compliance to take place. The patient should be informed that while a plant-based diet reduces the risk of stroke, it will also reduce the risk of a number of other diseases. This risk reduction of several diseases by one prescription may help maintain patient compliance as the perceived benefit is increased.

\section{Discussion}

The plant-based diet has the advantage of having no side effects, adverse reactions and no contraindications. It can also help prevent and treat a number of pathologies including common comorbidities of stroke patients. It is also very affordable for the patient. We live in an age of advanced medical technology. These advances have alleviated much suffering and saved countless lives. They have an unquestioned place in modern medicine. However, this can sometimes lead towards a kind of technological fundamentalism. Little notice is taken of treatments that, while lacking in technological sophistication, are nevertheless quite efficacious. Fortunately, many doctors have already started to integrate therapeutic plant-based diets into their patients' prevention and treatment of CAD. The former president of the American College of Cardiology, Dr. Kim Williams, uses this modality of treatment for his patients. In a recent article, he states

“ Unlike many of our cardiovascular prevention and treatment strategies, including antioxidants, vitamin $\mathrm{E}$, folic acid and niacin to name a few, that have disintegrated over time, the truth (i.e., evidence) for the benefits of plant-based nutrition continues to mount. This now includes lower rates of stroke, hypertension, diabetes mellitus, obesity, myocardial infarction and mortality, as well as many non-cardiac issues that affect our patients in cardiology, ranging from cancer to a variety of inflammatory conditions. Challenges with the science are, however, less daunting to overcome than inertia, culture, habit and widespread marketing of unhealthy foods. Our goal must be to get data out to the medical community and the public where it can actually change lives-creating healthier and longer ones " [86].

\section{References}

1. Mozaffarian D, Benjamin EJ, Go AS, Arnett DK, Blaha MJ, et al. (2015) Heart disease and stroke statistics--2015 update: a report from the American Heart Association. Circulation. 131(4): e29-e322.

2. Allen CL, Bayraktutan U (2008) Risk factors for ischaemic stroke. Int J Stroke. 3(2): 105-116.

3. Boehme AK, Esenwa C, Elkind MSV (2017) Stroke Risk Factors, Genetics, and Prevention. Circ Res 120(3): 472-495.

4. Adams Jr HP, Bendixen BH, Kappelle LJ, Biller J, Love B, et al. (1993) Classification of subtype of acute ischemic stroke. Definitions for use 


\section{Open Access Journal of Neurology \& Neurosurgery}

in a multicenter clinical trial. TOAST. Trial of Org 10172 in Acute Stroke Treatment. Stroke 24(1): 35-41.

5. Cheng NT, Kim AS (2015) Intravenous thrombolysis for acute ischemic stroke within 3 hours versus between 3 and 4.5 hours of symptom onset. Neurohospitalist 5(3): 101-109.

6. Reeves MJ, Arora S, Broderick JP, Frankel M, Heinrich JP, et al. (2005) Acute stroke care in the US: results from 4 pilot prototypes of the Paul Coverdell National Acute Stroke Registry. Stroke 36(6): 1232-1240.

7. Powers WJ, Rabinstein AA, Ackerson T, Adeoye OM, Bambakidis NC, et al. (2018) 2018 guidelines for the early management of patients with acute ischemic stroke: a guideline for healthcare professionals from the American Heart Association/American Stroke Association. Stroke 49(3): e46-e110.

8. Esenwa C, Gutierrez J (2015) Secondary stroke prevention: challenges and solutions. Vasc Health Risk Manag 11: 437-450.

9. Morgenstern LB, Hemphill JC, Anderson C, Becker K, Broderick JP (2010) American Heart Association Stroke Council and Council on Cardiovascular Nursing Guidelines for the management of spontaneous intracerebral hemorrhage: a guideline for healthcare professionals from the American Heart Association/American Stroke Association. Stroke 41(9): 2108-2129.

10. Steiner T, Salman RAS, Beer R, Christensen H, Cordoniier C, et al. (2014) European Stroke Organization (ESO) guidelines for the management of spontaneous intracerebral hemorrhage. Int J Stroke 9(7): 840-855.

11. Hsieh FI, Chiou HY (2014) Stroke: morbidity, risk factors, and care in Taiwan. J Stroke 16(2): 59-64.

12. O Donnell MJ, Chin SL, Rangarajan S, Xavier D, Liu L, et al. (2016) Glob al and regional effects of potentially modifiable risk factors associated with acute stroke in 32 countries (INTERSTROKE): a case-control study. Lancet 388(10046): 761-775.

13. Kim W, Kim E (2018) Heart Failure as a risk factor for stroke. J Stroke 20(1): 33-45

14. Ma YH, Leng XY, Dong Y, Xu W, Cao XP, et al. (2019) Risk factors for intracranial atherosclerosis: a systematic review and meta-analysis Atherosclerosis. 281: 71-77.

15. Okayama A, Okuda N, Miura K, Okamura T, Hayakawa T, et al. (2016) Dietary sodium-to-potassium ratio as a risk factor for stroke, cardiovascular disease and all-cause mortality in Japan: the NIPPON DATA80 cohort study. BMJ Open 6(7): e011632.

16. Strombom A, Rose S (2017) The prevention and treatment of Type II Diabetes Mellitus with a plant-based diet. Endocrin Metab Int J 5(5): 00138.

17. Rose S, Strombom A (2018) A comprehensive review of the prevention and treatment of heart disease with a plant-based diet. J Cardiol \& Cardiovasc Ther. 12(5): 555847.

18. Hoevenaar Blom MP, Nooyens ACJ, Kromhout D, Spijkerman A, Beulens, J, et al. (2012) Mediterranean style diet and 12-year incidence of cardiovascular diseases: the EPIC-NL cohort study. PLoS One 7(9) e45458

19. Kwok CS, Umar S, Myint PK, Mamas MA, Loke YK (2014) Vegetarian diet, Seventh Day Adventists and risk of cardiovascular mortality: a systematic review and meta-analysis. Int J Cardio 176(3): 680-686.

20. Chiu THT, Chang HR, Wang LY, Chang CC, Lin MN, et al. (2020) Vegetarian diet and incidence of total, ischemic, and hemorrhagic stroke in 2 cohorts in Taiwan. Neurology 94 (11): e1112-e1121.

21. Tong TYN, Appleby PN, Bradbury KE, Perez-Cornago A, Travis RC, et al. (2019) Risks of ischaemic heart disease and stroke in meat eaters, fish eaters, and vegetarians over 18 years of follow-up: results from the prospective EPIC-Oxford study. BMJ 366: 14897.

22. Ebrahim S, Sung J, Song YM, Ferrer RL, Lawlor DA, et al. (2006) Serum cholesterol, haemorrhagic stroke, ischaemic stroke, and myocardial infarction: Korean national health system prospective cohort study. BMJ 333(7557): 22.

23. Gillman MW, Cupples LA, Gagnon D, Posner BM, Ellison RC. et al. (1995) Protective effects of fruits and vegetables on development of stroke in men. JAMA 273(14): 1113-1117.

24. Gey KF, Stähelin HB, Eichholzer M. (1993) Poor plasma status of carotene and vitamin $\mathrm{C}$ is associated with higher mortality from ischemic heart disease and stroke Basel Prospective Study. Clin Invest Med 71(1): 3-6.

25. Khaw KT, Barrett-Connor E (1987) Dietary potassium and stroke-associated mortality. A 12-year prospective population study. N Engl J Med 316(5): 235-240.

26. Phillips RL, Lemon FR, Beeson WL, Kuzma JW (1978) Coronary heart disease mortality among Seventh Day Adventists with differing dietary habits: a preliminary report. Am J Clin Nutr 31(10 Suppl): S191-S198.

27. De Biase S, Fernandes S, Gianini R, Duarte J (2007) Vegetarian diet and cholesterol and triglycerides levels. Arquivos Brasileiros de Cardiologia 88(1): 35-39.

28. Thorogood M, Carter R, Benfield L, MCPherson K, Mann J (1987) Plasma lipids and lipoprotein cholesterol concentrations in people with different diets in Britain. Br Med J Clin Res Ed 295(6594): 351-353.

29. Haddad E, Berk L, Kettering J, Hubbard R, Peters W (1999) Dietary intake and biochemical, hematologic, and immune status of vegans compared with nonvegetarians. Am J Clin Nutr 70(3 Suppl): 586S-593S.

30. Bradbury KE, Crowe FL, Appleby PN, Schmidt JA, Travis RC, et al. (2014) Serum concentrations of cholesterol, apolipoprotein A-I and apolipoprotein B in a total of 1694 meat-eaters, fish-eaters, vegetarians and vegans. Eur J Clin Nutr 68(2): 178-183.

31. Kuchta A, Lebiedzińska A, Fijałkowski M, Gałąska R, Kreft E, et al (2016) Impact of plant-based diet on lipid risk factors for atherosclerosis. Cardiol J 23(2):141-148.

32. Glick-Bauer M, Yeh MC (2014) The Health Advantage of a Vegan Diet: Exploring the Gut Microbiota Connection. Nutrients. 6(11): 4822 4838.

33. Moon AR, Choi DH, Jahng SY, Kim BB, Seo HJ, et al. (2016) High-sensitivity C-reactive protein and mean platelet volume as predictive values after percutaneous coronary intervention for long-term clinical outcomes: a comparable and additive study. Blood Coagul Fibrinolysis 27(1): 70-76.

34. Jiménez MC, Rexrode KM, Glynn RJ, Ridker PM, Gaziano JM, et al. Association between high-sensitivity C-reactive protein and total stroke by hypertensive status among men. J Am Heart Assoc 4(9): e002073.

35. Zhou Y, Han W, Gong D, Man C, Fan Y (2016) Hs-CRP in stroke: A meta-analysis. Clin Chim Acta 453: 21-27.

36. Ridker PM (2016) A test in context: high-sensitivity C-reactive protein J Am Coll Cardiol 67(6): 712-723.

37. Huang X, Wang A, Liu X, Chen S, Zhu Y, et al. (2016) Association between high sensitivity C-Reactive protein and prevalence of asymptomatic carotid artery stenosis. Atherosclerosis 246: 44-49.

38. Rocco A, Ringleb PA, Grittner U, Nolte CH, Schneider A, et al. (2015) Follow-up C-reactive protein level is more strongly associated with outcome in stroke patients than admission levels. Neurol Sci 36(12): 2235-2241.

39. Szeto YT, Kwok TCY, Benzie IFF (2004) Effects of long-term vegetarian 


\section{Open Access Journal of Neurology \& Neurosurgery}

diet on biomarkers of antioxidant status and cardiovascular disease risk. Nutr 20(10): 863-866.

40. Haghighatdoost F, Bellissimo N, deZepetnek JOT, Rouhani MH (2017) Association of vegetarian diet with inflammatory biomarkers: a systematic review and meta-analysis of observational studies. Public Health Nutr 20(15): 2713-2721.

41. Shah B, Newman JD, Woolf K, Ganguzza L, Guo Y, et al. (2018) Anti-inflammatory effects of a vegan diet versus the American Heart Association-recommended diet in coronary artery disease trial. J Am Heart Assoc 7(23): e011367.

42. Fung TT, Chiuve SE, McCullough ML, Rexrode KM, Logroscino G, et al. (2008) Adherence to a DASH-style diet and risk of coronary heart disease and stroke in women. Arch Intern Med 168(7): 713-720.

43. Yokoyama Y, Nishimura K, Barnard ND, Takegami M, Watanabe M, et al. (2014) Vegetarian diets and blood pressure: a meta-analysis. JAMA Intern Med 174(4): 577-587.

44. Golzarand M, Bahadoran Z, Mirmiran P, Sadeghian-Sharif S, Azizi F (2015) Dietary phytochemical index is inversely associated with the occurrence of hypertension in adults: a 3-year follow-up (the Tehran Lipid and Glucose Study). Eur J Clin Nutr 69(3): 392-398.

45. Chuang SY, Chiu T, Lee CY, Liu TT, Tsao CK, et al. (2016) Vegetarian diet reduces the risk of hypertension independent of abdominal obesity and inflammation: a prospective study. J Hypertens 34(11): 21642171.

46. Fraser G, Katuli S, Anousheh R, Knutsen S, Herring P, et al. (2015) Vegetarian diets and cardiovascular risk factors in black members of the Adventist Health Study-2. Public Health Nutr 18(3): 537-545.

47. Chen R, Ovbiagele B, Feng W (2016) Diabetes and stroke: epidemiology, pathophysiology, pharmaceuticals and outcomes. Am J Med Sci 351(4): 380-386.

48. Tonstad S, Butler T, Yan R, Fraser GE (2009) Type of vegetarian diet, body weight, and prevalence of type 2 diabetes. Diabetes Care 32(5):791-796.

49. Go A, Reynolds K, Yang J, Gupta N, Lenane J, et al. (2018) Association of burden of atrial fibrillation with risk of ischemic stroke in adults with paroxysmal atrial fibrillation: The KP-RHYTHM Study. JAMA Cardiol 3(7): 601-608.

50. Stoddard M, Dawkins P, Prince C, Ammash N (1995) Left atrial appendage thrombus is not uncommon in patients with acute atrial fibrillation and a recent embolic event: a transesophageal echocardiographic study. J Am Coll Cardiol 25(2): 452-459.

51. Blackshear J, Odell J (1996) Appendage obliteration to reduce stroke in cardiac surgical patients with atrial fibrillation. Ann Thorac Surg 61(2): 755-759.

52. Brandes A, Smit MD, Nguyen BO, Rienstra M, Gelder ICV. (2018) Risk factor management in atrial fibrillation. Arrhythm Electrophysiol Rev $7(2): 118-127$.

53. Wyse DG, Gelder ICV, Ellinor PT, Go AS, Kalman JM, et al. (2014) Lone atrial fibrillation: does it exist? J Am Coll Cardiol 63(17): 1715-1723.

54. Gallagher C, Hendriks JML, Mahajan R, Middeldorp ME, Elliott AD, et al. (2016) Lifestyle management to prevent and treat atrial fibrillation. Expert Rev Cardiovasc Ther 14(7): 799-809.

55. Vermond RA, Geelhoed B, Verweij N, Tieleman RG, Van der Harst P, et al. (2015) Incidence of atrial fibrillation and relationship with cardiovascular events, heart failure, and mortality: a community-based study from the Netherlands. J Am Coll Cardiol 66(9): 1000-1007.

56. Storz MA, Helle P (2019) Atrial fibrillation risk factor management with a plant-based diet: A review. J Arrhythm 35(6): 781-788.
57. Joshi S, Ettinger L, Liebman SE (2019) Plant-based diets and hypertension. An J Lifestyle Med 14(4): 397-405.

58. Alexander S, Ostfeld RJ, Allen K, Williams KA (2017) A plant-based diet and hypertension. J Geriatr Cardiol 14(5): 327-330.

59. Rose S, Strombom A (2020) Preventing thyroid diseases with a plantbased diet, while ensuring adequate iodine status. Glob J Oto 21(4) 556069 .

60. Tonstad S, Nathan E, Oda K, Fraser GE (2015) Prevalence of hyperthyroidism according to type of vegetarian diet. Public Health Nutr. 18(8): 1482-1487.

61. Rose S, Strombom A (2019) A plant-based diet prevents and treats chronic kidney disease. JOJ Uro \& Nephron 6(3): 555687.

62. Brouwer IA, Heeringa J, Geleijnse JM, Zock PL, Witteman JCM, et al. (2006) Intake of very long-chain n-3 fatty acids from fish and incidence of atrial fibrillation. The Rotterdam Study. Am Heart J 151(4): 857-862.

63. Li FR, Chen GC, Qin J, Wu X (2017) Dietary fish and long-chain n-3 polyunsaturated fatty acids intake and risk of atrial fibrillation: a metaanalysis. Nutrients 9(9): 955.

64. Velagaleti R, Vasan R (2007) Heart Failure in the 21st Century: Is it a Coronary Artery Disease Problem or Hypertension Problem? Cardiol Clin 25(4): 487-495.

65. Djoussé L, Driver J, Gaziano J (2009) Relation between modifiable lifestyle factors and lifetime risk of heart failure. JAMA. 302(4): 394-400.

66. Wang Y, Tuomilehto J, Jousilahti P, Antikainen R, Mähönen M, et al. (2011) Lifestyle factors in relation to heart failure among Finnish men and women. Circ Heart Fail 4(5): 607-612.

67. Pfister R, Sharp S, Luben R, Wareham N, Khaw K (2011) Plasma vitamin $\mathrm{C}$ predicts incident heart failure in men and women in European Prospective Investigation into Cancer and Nutrition-Norfolk prospective study. Am Heart J 162(2): 246-53.

68. Rautiainen S, Levitan E, Mittleman M, Wolk A (2015) Fruit and vegetable intake and rate of heart failure: a population-based prospective cohort of women. Eur J Heart Fail 17(1): 20-26.

69. Choi E, Allen K, Mc Donnough M, Massera D, Ostfeld R (2017) A plantbased diet and heart failure: case report and literature review. J Geriatr Cardiol 14(5): 375-378.

70. Wirth J, di Giuseppe R, Boeing H, Weikert C (2016) A Mediterranean style diet, its components and the risk of heart failure: a prospective population-based study in a non-Mediterranean country. Eur J Clin Nutr 70(9): 1015-1021.

71. Nettleton J, Steffen L, Loehr L, Rosamond W, Folsom A (2008) Incident heart failure is associated with lower whole-grain intake and greater high-fat dairy and egg intake in the Atherosclerosis Risk in Communities (ARIC) study. J Am Diet Assoc 108(11): 1881-1887.

72. Ashaye A, Gaziano J, Djoussé L (2011) Red meat consumption and risk of heart failure in male physicians. Nutr Metab Cardiovasc Dis 21(12): 941-946.

73. Kaluza J, Åkesson A, Wolk A (2015) Long-term processed and unprocessed red meat consumption and risk of heart failure: a prospective cohort study of women. Int J Cardiol 193: 42-46.

74. Kerley CA (2018) Review of Plant-based Diets to Prevent and Treat Heart Failure. Card Fail Rev 4(1): 54-61.

75. Djoussé L, Gaziano J (2008) Egg consumption and risk of heart failure in the Physicians' Health Study. Circulation 117(4): 512-516.

76. Lara K, Levitan E, Guitterrez O, Shikany J, Safford MJS, et al. (2017) Dietary patterns and incident heart failure in adults with no known 
coronary disease or heart failure: The REGARDS Cohort. Circulation 136(Suppl 1).

77. Pischke C, Weidner G, Elliott-Eller M, Ornish D (2007) Lifestyle changes and clinical profile in coronary heart disease patients with an ejection fraction of $40 \%$ in the Multicenter Lifestyle Demonstration Project. Eur J Heart Fail 9(9): 928-934.

78. Allen KE, Gumber D, Ostfeld RJ (2019) Heart failure and a plant-based diet. A case-report and literature review. Front Nutr. 6: 82.

79. Bloomer R, Kabir M, Canale R, Trepanowski J, Marshall K, et al. (2010) Effect of a 21-day Daniel Fast on metabolic and cardiovascular disease risk factors in men and women. Lipids Health Dis 9: 94.

80. Barnard N, Cohen J, Jenkins D, Turner-McGrievy G, Gloede L, et al. (2006) A low-fat vegan diet improves glycemic control and cardiovascular risk factors in a randomized clinical trial in individuals with type 2 diabetes. Diabetes Care 29(8): 1777-1783.

81. Kahleova H, Matoulek M, Bratova M, Malinska H, Kazdova L (2013) Vegetarian diet-induced increase in linoleic acid in serum phospholip- ids is associated with improved insulin sensitivity in subjects with type 2 diabetes. Nutr Diabetes 3: e75.

82. Esselstyn CJ, Gendy G, Doyle J, Golubic M, Roizen M (2014) A way to reverse CAD? J Fam Pract. 63(7): 356-364b.

83. Drozek D, Diehl H, Nakazawa M, Kostohryz T, Morton D, et al. (2014) Short-term effectiveness of a lifestyle intervention program for reducing selected chronic disease risk factors in individuals living in rural appalachia: a pilot cohort study. Adv Prev Med 2014:798184.

84. Jenkins D, Kendall C, Marchie A, Faulkner DW, Wong JMW, et al. (2005) Direct comparison of a dietary portfolio of cholesterol-lowering foods with a statin in hypercholesterolemic participants. Am J Clin Nutr 81(2): 380-387.

85. Ornish D, Scherwitz L, Billings J, Brown S, Gould KL, et al. (1998) Intensive Lifestyle Changes for Reversal of Coronary Heart Disease. JAMA280 (23): 2001-2007.

86. Williams K (2017) Introduction to the A plant-based diet and cardiovascular disease special issue. J Geriatr Cardiol 14(5): 316.

\section{Your next submission with Juniper Publishers will reach you the below assets}

- Quality Editorial service

- Swift Peer Review

- Reprints availability

- E-prints Service

- Manuscript Podcast for convenient understanding

- Global attainment for your research

- Manuscript accessibility in different formats

\section{( Pdf, E-pub, Full Text, Audio)}

- Unceasing customer service

Track the below URL for one-step submission

https://juniperpublishers.com/online-submission.php 